\title{
Factors Associated with the Use of Fecal Immunochemical Tests and Colonoscopy in the INSEF Portuguese Population
}

\author{
Fábio Sousa Gomes $^{a}$ Irina Kislaya ${ }^{b, c}$ Dulce Seabra ${ }^{a}$ Eugénio Cordeiro ${ }^{d}$ \\ Baltazar Nunes ${ }^{\text {b, }}$

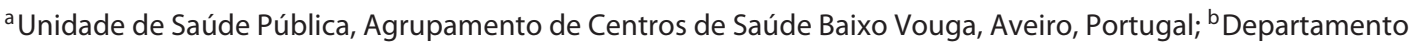 \\ de Epidemiologia, Instituto Nacional de Saúde Doutor Ricardo Jorge, Lisbon, Portugal; ' ${ }^{C}$ Centro de Investigação \\ em Saúde Pública, Escola Nacional de Saúde Pública, Universidade Nova de Lisboa, Lisbon, Portugal; ' Unidade \\ de Investigação e Planeamento em Saúde, Departamento de Saúde Pública, Administração Regional de Saúde do \\ Centro, Coimbra, Portugal
}

\author{
Keywords \\ Colorectal cancer · Colonoscopy · Fecal immunochemical \\ test $\cdot$ Health examination survey
}

\begin{abstract}
Introduction: The incidence of colorectal cancer is increasing worldwide. However, the screening uptake is generally low. We analyzed the association between sociodemographic, economic, and access-to-healthcare factors and the use of exams that are the basis for colorectal cancer screening in Portugal. Methods: We conducted a cross-sectional study based on data from the 1st National Health Examination Survey. We used Poisson regression to estimate prevalence ratios and study factors associated with the use of fecal immunochemical tests (FIT) and colonoscopy in a Portuguese population aged $50-74$ years $(n=2,489)$. Results: $45.7 \%$ of the individuals reported using FIT in the previous 2 years; $37.3 \%$ reported using colonoscopy in the previous 5 years. The use of FIT was associated with age group, health region, and having a family doctor. It was higher in older in-
\end{abstract}

dividuals (47.6\% in the age group $70-74$ years vs. $38.1 \%$ in the age group 50-54 years; adjusted prevalence ratio [aPR] $=1.32 ; 95 \% \mathrm{Cl} 1.05-1.65)$, and in individuals assigned to a family doctor (47.6 vs. 30.3\%; aPR $=1.50 ; 95 \% \mathrm{Cl} 1.14-1.98$ ). Colonoscopy was associated with age group, health region, higher education, economic capacity, and having a family doctor. It was higher in older individuals $145.3 \%$ in the age group $70-74$ years vs. $25.6 \%$ in the age group $50-54$ years; $\mathrm{aPR}=1.85 ; 95 \% \mathrm{Cl} 1.42-2.40)$, individuals with a higher economic capacity (40.5 vs. 32.4\%; aPR = 1.19; $95 \% \mathrm{Cl} 1.01-1.40$ ), and individuals assigned to a family doctor (38.7 vs. $25.6 \%$; $\mathrm{aPR}=1.43 ; 95 \% \mathrm{Cl} 1.08-1.91)$. Discussion/Conclusion: In our analysis, the use of FIT and colonoscopy was influenced by sociodemographic, economic, and access-to-healthcare factors. This is relevant to guide interventions in this area. It is essential to ensure an equitable and uniform implementation of the screening program, with family doctors as an important part of the process.

C 2021 The Author(s). Published by S. Karger AG, Base on behalf of NOVA National School of Public Health (c) 2021 The Author(s). Published by S. Karger AG, Basel on behalf of NOVA National School of Public Health

This is an Open Access article licensed under the Creative Commons Attribution-NonCommercial-4.0 International License (CC BY-NC) (http://www.karger.com/Services/OpenAccessLicense), applicable to the online version of the article only. Usage and distribution for commercial purposes requires written permission.
Correspondence to:

Fábio Sousa Gomes, fabiosgomes.sp@gmail.com 
Fatores associados com a utilização de pesquisa de sangue oculto nas fezes e colonoscopia na população Portuguesa do INSEF

\section{Palavras Chave}

Cancro Colorretal · Colonoscopia · Pesquisa de Sangue Oculto nas Fezes · Inquérito Nacional de Saúde com Exame Físico

\section{Resumo}

Introdução: A incidência de cancro colorretal está a aumentar em todo o Mundo. Porém, a adesão ao rastreio é baixa. Foi analisada a associação entre fatores sociodemográficos, económicos e de acesso aos cuidados de saúde, e o uso dos exames que servem de base ao rastreio do cancro colorretal em Portugal. Métodos: Estudo transversal, com base nos dados do $1^{\circ}$ Inquérito Nacional de Saúde com Exame Físico. Foi utilizada regressão de Poisson para estimar razões de prevalência e estudar os fatores associados com o uso de pesquisa de sangue oculto nas fezes (FIT) e colonoscopia na população portuguesa com 50-74 anos ( $n=2,489)$. Resultados: $45.7 \%$ dos indivíduos reportaram ter realizado FIT nos 2 anos anteriores. $37,3 \%$ reportaram ter realizado colonoscopia nos 5 anos anteriores. O uso de FIT apresentou associação com grupo etário, região de saúde e médico de família. Foi maior nos indivíduos mais velhos $(47.6 \%$ no grupo etário dos 70-74 anos vs. $38.1 \%$ no grupo etário dos $50-54$ anos aRP $=1.32[1.05 ; 1.65])$, e com médico de família atribuído (47.6\% vs. $30.3 \%$, aRP $=1.5[1.14 ; 1.98])$. O uso de colonoscopia apresentou associação com grupo etário, região de saúde, ensino superior, capacidade económica e médico de família. Foi maior nos indivíduos mais velhos (45.3\% no grupo etário dos $70-74$ anos vs. $25.6 \%$ no grupo etário dos 50-54 anos, aRP = 1.85 [1.42; 2.40]), com maior capacidade económica $(40.5 \%$ vs. $32.4 \%$, aRP $=1.19[1.01$; 1.40]) e com médico de família ( $38.7 \%$ vs. $25.6 \%$, aRP $=$ 1.43 [1.08; 1.91]). Discussão/Conclusão: O uso de FIT e de colonoscopia apresentou associação com fatores sociodemográficos, económicos e de acesso aos cuidados de saúde. Tal associação é relevante para orientar a intervenção nesta área. É essencial garantir uma implementação equitativa e uniforme do rastreio, sendo os médicos de família importantes neste processo.

(c) 2021 The Author(s). Published by S. Karger AG, Basel on behalf of NOVA National School of Public Healthl

Use of FIT and Colonoscopy in Portugal

\section{Introduction}

The worldwide incidence of cancer has been steadily increasing by around 3\% per year [1]. The European continent accounts for about a quarter of the global cancer burden [2]. Neoplasms are currently the second leading cause of death [3], as well as the second leading cause of premature death $[4,5]$. According to the latest data from the International Agency for Research on Cancer, colorectal cancer (CRC) is the second most common and second most deadly neoplasm in Europe [6]. In Portugal, it is the most common neoplasm in both sexes, having been responsible for 10,501 new cases (more than 28 cases per day) and 4,275 deaths (about 12 people per day) in 2020 [6].

The reduction in cancer mortality and morbidity depends mainly on preventive strategies, with an emphasis on population screening [4, 7]. Several studies have demonstrated the effectiveness of the main screening exams in reducing the incidence and mortality caused by CRC in the long term, although strategies vary between countries $[8,9]$. Portugal follows the European guidelines, according to which screening should be offered to all asymptomatic individuals between 50 and 74 years of age [10-12]. The primary screening test is the fecal immunochemical test (FIT), which should be performed every 2 years. If the FIT has a positive result, the patient must be referred to colonoscopy $[10,11]$.

However, CRC screening programs usually present a low population coverage, even in populations where the program has been implemented for a long time, which suggests the existence of mediating factors that go beyond those of an organizational nature [13, 14].

Several studies have suggested that people tend to overestimate their need to use preventive care, so the low coverage of screening programs may not be related to a lack of intention or a lack of recognition of its importance by patients but rather to other factors $[15,16]$. The influence of sociodemographic, economic, and access-tohealthcare factors in the use of preventive services has been widely demonstrated $[17,18]$. It is important to understand how these factors are associated with the exams used in CRC screening in particular.

This study aims to estimate the association between sociodemographic, economic, and access-to-healthcare factors, and the use of the exams that are the basis for CRC screening, in the Portuguese population aged between 50 and 74 years. The conclusions may support planning for more effective and targeted interventions in this area. 


\section{Materials and Methods}

\section{Study Design}

We developed a cross-sectional, observational, epidemiological study using self-reported data from the first Portuguese National Health Examination Survey (INSEF), collected by interview between February and December 2015. INSEF 2015 was performed on a representative, probabilistic sample $(n=4,911)$ of noninstitutionalized individuals aged 25-74 years who had been living in Portugal for more than 12 months and were able to follow the interview in Portuguese. For this study, the target population was restricted to individuals between 50 and 74 years of age in order to match the eligible population for CRC screening in Portugal $(n=$ 2,489 ). Details on the sample design and methods used for the survey can be consulted in previous publications [19].

The variables of interest for this study were collected through a computer-assisted personal interview using REDCap (Research Electronic Data Capture) software [20].

\section{Variables}

The variables included in this study were either selected or adapted from the INSEF database. The dependent variables reflect whether or not each individual used FIT or colonoscopy. The use of FIT and colonoscopy was assessed by the questions: "When was the last time that you used a fecal occult blood test?" and "When was the last time you used a colonoscopy?", with the following possible answers:

- Less than 3 months;

- Between 3 and 5 months;

- Between 6 and 11 months;

- 12 months or more (indicate the number of years); and

- Never.

Classification of the individuals as users or nonusers was done according to the following timings:

- User of FIT: the individual reported having used the exam in the previous 2 years; and

- User of colonoscopy: the individual reported having used the exam in the previous 5 years.

The timings above were chosen based on European guidelines for CRC screening [11] and for colonoscopy surveillance [21], with a consensus achieved by consultation with national experts.

The independent variables reflect the sociodemographic (sex, age group, health region, degree of urbanization, and education level), economic (employment status and economic capacity), and access to healthcare (having a family doctor) factors of interest. The degree of urbanization was determined based on the Portuguese TIPAU classification (typology of urban area) - the primary sampling units in which more than $50 \%$ of the population resided in a "predominantly urban area" according to TIPAU were classified as "urban;" otherwise, they were classified as "rural" [19].

Having a family doctor means having an assigned general practitioner or family medicine specialist in the primary care setting who attends the individual's medical needs in a comprehensive manner.

\section{Statistical Analysis}

Since all variables were categorical, the corresponding absolute and relative frequencies were calculated. To compare the proportion of individuals who used each exam between different population subgroups, a design-adjusted $\chi^{2}$ test was applied. Factors associated with the use of each exam were analyzed using a multi-
Table 1. Characteristics of the study participants

\begin{tabular}{|c|c|}
\hline Characteristic & $\begin{array}{l}\text { Participants, } \\
n(\%)^{\mathrm{a}}\end{array}$ \\
\hline FIT & 2,295 \\
\hline No & $1,432(54.3)$ \\
\hline Yes & $863(45.7)$ \\
\hline Colonoscopy & 2,430 \\
\hline No & $748(62.7)$ \\
\hline Yes & $1,682(37.3)$ \\
\hline Age group (years) & 2,489 \\
\hline $50-54$ & $620(24.3)$ \\
\hline $55-59$ & $540(20.0)$ \\
\hline $60-64$ & $558(22.1)$ \\
\hline $65-69$ & $432(18.7)$ \\
\hline $70-74$ & $339(15.0)$ \\
\hline Sex & 2,489 \\
\hline Female & $1,318(53.5)$ \\
\hline Male & $1,171(46.5)$ \\
\hline Health region & 2,489 \\
\hline North & $414(36.2)$ \\
\hline Center & $349(16.7)$ \\
\hline Lisbon and Tagus Valley & $318(33.7)$ \\
\hline Alentejo & $367(4.9)$ \\
\hline Algarve & $332(4.0)$ \\
\hline Autonomous region of Madeira & $370(2.4)$ \\
\hline Autonomous region of Azores & $339(2.0)$ \\
\hline Degree of urbanization & 2,489 \\
\hline Rural & $727(27.5)$ \\
\hline Urban & $1,762(72.5)$ \\
\hline Education level & 2,486 \\
\hline Elementary school & $1,308(50.0)$ \\
\hline Middle school & $673(28.3)$ \\
\hline Secondary school & $285(12.0)$ \\
\hline Higher education & $220(9.7)$ \\
\hline Employment status & 2,487 \\
\hline Employed & $992(37.7)$ \\
\hline Unemployed & $231(10.0)$ \\
\hline Other & $1,264(52.2)$ \\
\hline Economic capacity & 2,456 \\
\hline No & $1,029(38.1)$ \\
\hline Yes & 1,427 (61.9) \\
\hline Family doctor & 2,483 \\
\hline No & $431(11.5)$ \\
\hline Yes & $2,052(88.5)$ \\
\hline
\end{tabular}

a Relative frequencies weighted for the distribution of the resident population in Portugal, in 2015, by health region, sex, and age group.

variate Poisson regression model. The magnitude of associations was measured using adjusted prevalence ratios (aPR) with 95\% CI. The choice of using prevalence ratios was due to the cross-sectional nature of the study and because OR estimated by logistic regression often overestimate the effect when the outcome under study is frequent $[22,23]$. The model's goodness of fit was verified using the $p$ value of the likelihood ratio test [24]. 
Table 2. Use of the FIT by sex, age group, health region, degree of urbanization, education level, employment status, economic capacity, and family doctor

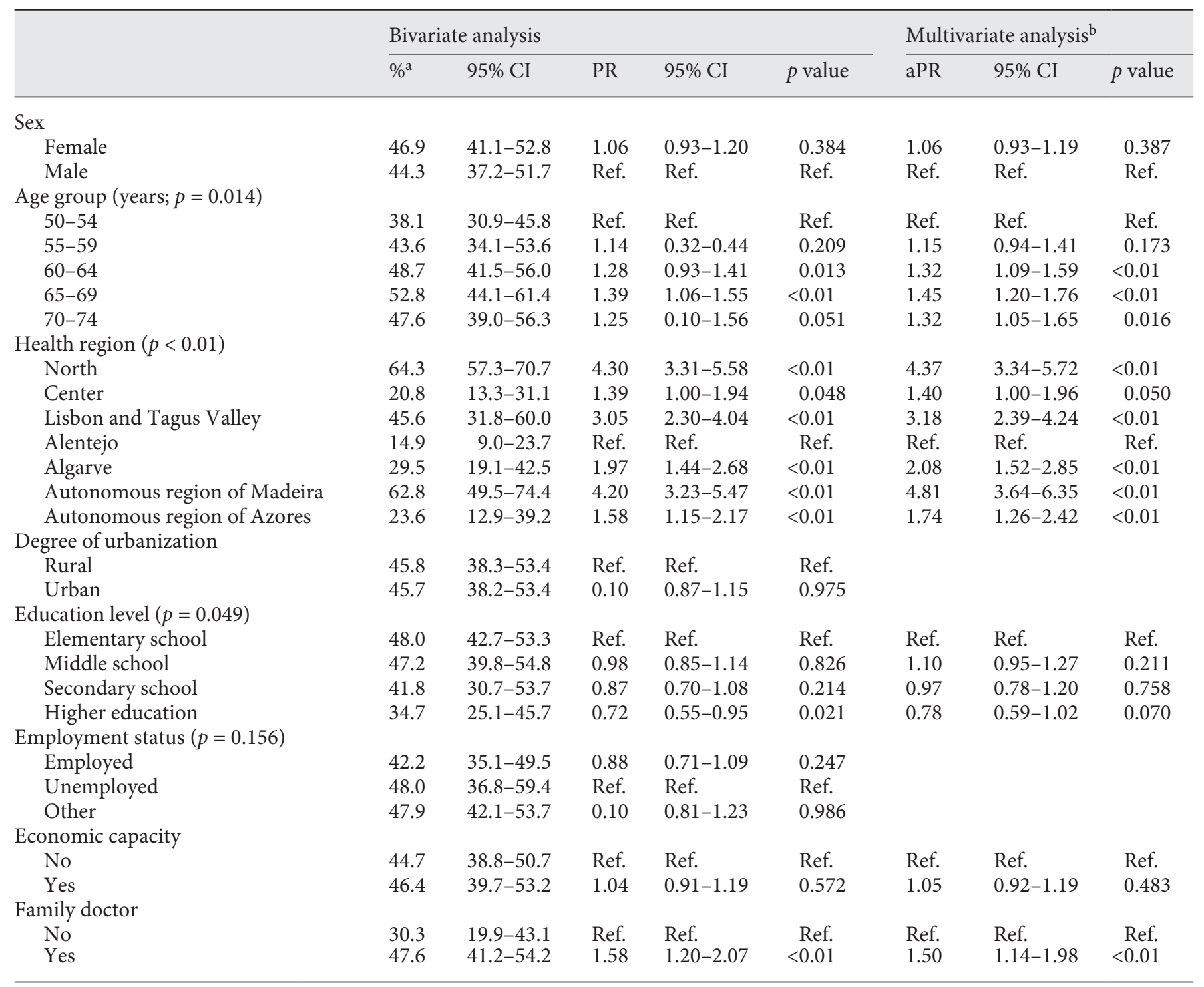

Ref., reference. ${ }^{\text {a }}$ Relative frequencies weighted for the distribution of the resident population in Portugal, in 2015, by health region, sex, and age group. ${ }^{\mathrm{b}}$ Poisson regression model.

$p<0.05$ was considered statistically significant. The statistical analysis was performed using the Survey Package of R [25]. All statistical analyses were performed using sampling weights to provide national representativeness.

\section{Results}

The participants' characteristics are described in Table 1. The final sample consisted of 2,295 individuals, $53.5 \%$ of whom were females; $11.5 \%$ of the individuals reported not having an assigned family doctor; $45.7 \%$ reported having used FIT in the previous 2 years, and $37.3 \%$ reported having used colonoscopy in the previous 5 years.

\section{Factors Associated with the Use of FIT}

The results of the bivariate and multivariate analyses of the factors associated with the use of FIT are described in Table 2.

The use of FIT was associated with age group, health region, and having a family doctor. No statistically significant association was verified, through multivariate 
Table 3. Use of colonoscopy by sex, age group, health region, degree of urbanization, education level, employment status, economic capacity, and family doctor

\begin{tabular}{|c|c|c|c|c|c|c|c|c|}
\hline & \multicolumn{5}{|c|}{ Bivariate analysis } & \multicolumn{3}{|c|}{ Multivariate analysis ${ }^{\mathrm{b}}$} \\
\hline Female & 35.3 & $31.1-39.7$ & 0.89 & $0.77-1.03$ & 0.12 & 0.88 & $0.76-1.02$ & 0.088 \\
\hline Male & 39.6 & $36.0-43.3$ & Ref. & Ref. & Ref. & Ref. & Ref. & Ref. \\
\hline \multicolumn{9}{|l|}{ Age group (years; $p<0.01$ ) } \\
\hline $60-64$ & 42.0 & $35.6-48.7$ & 1.63 & $1.29-2.08$ & $<0.01$ & 1.68 & $1.32-2.14$ & $<0.01$ \\
\hline $65-69$ & 40.2 & $35.7-44.8$ & 1.57 & $1.22-2.01$ & $<0.01$ & 1.61 & $1.24-2.08$ & $<0.01$ \\
\hline $70-74$ & 45.3 & $39.0-51.8$ & 1.77 & $1.37-2.28$ & $<0.01$ & 1.85 & $1.42-2.40$ & $<0.01$ \\
\hline \multicolumn{9}{|l|}{ Health region $(p<0.01)$} \\
\hline North & 40.5 & $33.5-47.9$ & 1.62 & $1.30-2.01$ & $<0.01$ & 1.64 & $1.32-2.05$ & $<0.01$ \\
\hline Center & 40.9 & $34.5-47.6$ & 1.64 & $1.31-2.04$ & $<0.01$ & 1.61 & $1.28-2.02$ & $<0.01$ \\
\hline Autonomous region of Azores & 20.6 & $17.8-23.8$ & 0.83 & $0.62-1.09$ & 0.179 & 0.87 & $0.65-1.16$ & 0.328 \\
\hline \multicolumn{9}{|l|}{ Degree of urbanization } \\
\hline Rural & 37.0 & $29.2-45.6$ & Ref. & Ref. & Ref. & & & \\
\hline Urban & 37.4 & $34.0-40.9$ & 1.01 & $0.86-1.18$ & 0.909 & & & \\
\hline \multicolumn{9}{|l|}{ Education level $(p=0.107)$} \\
\hline Elementary school & 37.3 & $32.6-42.3$ & Ref. & Ref. & Ref. & Ref. & Ref. & Ref. \\
\hline Middle school & 34.3 & $31.0-37.8$ & 0.92 & $0.77-1.10$ & 0.364 & 1.06 & $0.87-1.27$ & 0.574 \\
\hline Secondary school & 36.8 & $27.8-46.9$ & 0.99 & $0.78-1.25$ & 0.917 & 1.08 & $0.85-1.37$ & 0.534 \\
\hline Higher education & 46.5 & $38.0-55.1$ & 1.25 & $1.00-1.55$ & 0.049 & 1.38 & $1.10-1.73$ & $<0.01$ \\
\hline \multicolumn{9}{|l|}{ Employment status $(p<0.01)$} \\
\hline Employed & 34.0 & $29.4-38.9$ & 1.23 & $0.90-1.69$ & 0.19 & & & \\
\hline
\end{tabular}

Ref., reference. ${ }^{\text {a }}$ Relative frequencies weighted for the distribution of the resident population in Portugal, in 2015 , by health region, sex, and age group. ${ }^{\text {b }}$ Poisson regression model.

analysis, between the use of FIT and the variables sex, degree of urbanization, education level, employment status, and economic capacity.

The use of FIT by individuals increased proportionally with age, although the highest proportion was in the age group 65-69 years (compared to the age group 50-54 years; 52.8 vs. $38.1 \%$; $\mathrm{aPR}=1.45 ; 95 \%$ CI $1.20-1.76$ ). The oldest age group, i.e., 70-74 years, also registered a higher proportion of FIT use (compared to the age group 5054 years, 47.6 vs. $38.1 \%$; aPR = 1.32; 95\% CI 1.05-1.65).
A statistically significant association between health region and FIT use was confirmed for all regions. The highest proportions of FIT use were registered in the northern region of Portugal (64.3\%; aPR $=4.37 ; 95 \% \mathrm{CI}$ 3.34-5.72) and in the autonomous region of Madeira $(62.8 \% ; \mathrm{aPR}=4.81 ; 95 \%$ CI 3.64-6.35), in comparison to the Alentejo region, which registered the lowest value (14.9\%).

There was a decreasing gradient in the use of FIT with higher levels of education, with the lowest value being 
registered in individuals with the highest levels of education (compared to individuals with no formal education or only elementary school; 34.7 vs. $48.0 \%$; $\mathrm{aPR}=0.78$; $95 \%$ CI 0.59-1.02). In the multivariate analysis, however, the level of education did not show a statistically significant association with the use of FIT, regardless of the category.

The use of FIT was higher in individuals with an assigned family doctor ( 47.6 vs. $30.3 \%$; $\mathrm{aPR}=1.50 ; 95 \% \mathrm{CI}$ 1.14-1.98).

\section{Factors Associated with the Use of Colonoscopy}

The results of the bivariate and multivariate analyses of the factors associated with the use of colonoscopy are described in Table 3.

Colonoscopy was associated with age group, health region, employment status, economic capacity, and having a family doctor. Regarding the level of education, a statistically significant association was found between having a higher education and using colonoscopy (compared to individuals with no formal education or only elementary school; 46.5 vs. $37.3 \%$; aPR $=1.38$; $95 \%$ CI $1.10-1.73$ ), but not for the remaining categories of the variable. No statistically significant association was verified, through multivariate analysis, between the use of colonoscopy and the variables sex and degree of urbanization.

Age group was statistically associated with the use of colonoscopy, regardless of the category. There was an increase in the use of colonoscopy with advancing age, with the highest value registered in the age group 70-74 years (compared to the age group $50-54$ years; 45.3 vs. $25.6 \%$; $\mathrm{aPR}=1.85 ; 95 \%$ CI $1.42-2.40)$.

Only the North, Center, and Lisbon and Tagus Valley regions of Portugal showed an association with the use of colonoscopy. The Center $(40.9 \%$; aPR $=1.61 ; 95 \%$ CI $1.28-2.02)$ and North (40.5\%; aPR $=1.64$; $95 \%$ CI $1.32-$ 2.05) regions of Portugal registered the highest proportions of colonoscopy users in the country, in contrast to the Alentejo region, which registered the lowest (25.0\%).

Regarding the employment status, the highest value of colonoscopy use was registered in the class of individuals without a rewarded professional activity (pensioners, retirees, domestic workers, or students, compared to unemployed individuals; 41.6 vs. $27.6 \%$; $\mathrm{PR}=1.51 ; 95 \% \mathrm{CI}$ 1.12-2.04).

Colonoscopy use was statistically higher in the class of individuals with a higher economic capacity (40.5 vs. $32.4 \%$; $\mathrm{aPR}=1.19 ; 95 \% \mathrm{CI} 1.01-1.40)$ and those with an assigned family doctor ( 38.7 vs. $25.6 \%$; aPR $=1.43$; $95 \%$ CI 1.08-1.91).

Use of FIT and Colonoscopy in Portugal

\section{Discussion}

\section{Main Findings}

This study, based on a large probabilistic sample, representative of the Portuguese population aged 50-74 years, suggests that the use of FIT and colonoscopy is influenced by sociodemographic, economic, and access-tohealthcare factors.

At the national level, the proportion of individuals who reported having used FIT in the previous 2 years was $45.7 \%$. The proportion of individuals who reported having used colonoscopy in the previous 5 years was 37.3\%.

The use of FIT was associated with age group (higher in older individuals), health region, and having an assigned family doctor. The use of colonoscopy was associated with age group (higher in older individuals), health region, a higher education, a higher economic capacity, and having an assigned family doctor.

\section{Comparison with Existing Literature}

In our study, we found higher proportions of exam users than those found in other studies. The last European Health Interview Survey (EHIS 2) found that $35.8 \%$ of the Portuguese population had used FIT in the previous 2 years, and $17.2 \%$ had used colonoscopy in the previous 10 years (31.3 and $12 \%$, respectively, in the European Union) [26]. A recent Portuguese study suggested that $17.1 \%$ of the Portuguese population "usually undergoes" FIT [15]. Another study showed a lifetime prevalence of screening for CRC of 23.7\% [27]. The 2014 National Health Survey (NHS) found that $35.6 \%$ of the Portuguese population had used FIT in the previous 2 years and $35.1 \%$ had undergone a colonoscopy in the previous 10 years [28]. However, due to the noted methodological differences, comparisons should be made with caution.

It is interesting to notice that the proportions of individuals who used each of the exams, in each of the health regions of the country, do not match what would be expected given the implementation of the CRC screening program in Portugal at the time. At the time the INSEF database was made (2015), a CRC screening program had only been implemented in the Center, Alentejo, and Azores health regions [14], precisely the 3 regions that registered the lowest proportions of FIT use by individuals. Similar results were already reported in the 2014 NHS [28], so this must not be ignored and deserves further investigation. One possible explanation for this may be implementation of the screening program in a way that does not comply with current recommendations. Even in the regions where the screening program was already implemented, it was in 
an early stage. The incipient implementation of the CRC screening program, which persists to this day, favors the use of opportunistic "screening" acts rather than the necessary population-based screening program, i.e., use of opportunistic colonoscopies instead of FIT as the primary exam. This hypothesis may be supported, for example, by the fact that the Center region of Portugal registered the second lowest proportion of users of FIT in this study, but the highest proportion of users of colonoscopy. We point out, however, that the health regions of Portugal correspond to large geographic areas, with important differences between them but also within its territory. This reality makes conclusions and comparisons more difficult to assess.

None of the exams showed a statistically significant association with the variables sex and degree of urbanization. The influence of sex is not consensual in the literature. Although, classically, a higher uptake is described among males [29], several studies point to the opposite direction $[30,31]$. Others suggest that it depends on the exam, with a greater uptake of FIT by females and of colonoscopy by males $[32,33]$. However, as in this study, a large number of studies have not found statistically significant differences between genders [32, 34], which is corroborated by 2 other recent national studies [15, 27].

Regarding the degree of urbanization, older studies tend to describe a greater screening uptake in urban areas [29]. However, a study showed that in recent years the FIT uptake has increased more in rural areas than in urban areas [34], which may indicate that the previous unevenness was mainly due to a lack of access to information and healthcare services. In a small country, such as Portugal, it is also less likely that differences related to this variable will be found.

The influence of economic capacity is in line with what has been described in other studies, which demonstrate that the level of income influences the use of colonoscopy more significantly than that of FIT, even when its use is motivated by a positive FIT [30]. Although in Portugal screening acts are free of charge for individuals, the limited response capacity of the National Health Service and the use of opportunistic colonoscopies often motivates the use of private health services and, therefore, payment or copayment by the individual. Since the beginning of the current year, however, there is no copayment for exams prescribed by the family doctor within private units with convention with the National Health Service, which may influence these results.

A statistically significant association was found between age group and the use of both FIT and colonoscopy, in accordance with the literature in the description of an increasing use with advancing age, especially over 60 65 years $[29,32]$.

Having a higher education level showed a statistically significant association with the use of both FIT and colonoscopy, though in opposite directions. Contrary to colonoscopy, having a higher education seems to decrease the possibility of using FIT. These results were already described in the NHS of 2014 [28], but they do not match what has been observed at the European level, where the highest values of FIT use occur in the most educated population [35]. Although these results require further investigation, a possible explanation lies in the differential use of exams by individuals with different levels of education. Since the use of colonoscopy is positively influenced by the economic level [30], these results may be due to the relationship between a higher level of education and a higher income. In the multivariate analysis, the level of education showed no statistically significant association with the use of FIT. This may be due to the relationship that the level of education has with other variables of the model, such as sex and age. However, in multivariate analysis, it maintained a statistically significant association with the use of colonoscopy, which seems to corroborate the presented interpretation.

Having an assigned family doctor showed a positive association with the use of both exams. The importance of having a regular caregiver is consistently described in the literature $[36,37]$. The effect may be due to the role that family doctors play in educational intervention and health literacy throughout life. Systematic contact with patients allows a more personalized and user-friendly approach, improving the screening uptake through strategies like personal invitation letters, reminders, and discussion during visits [37]. However, an organized screening model that is more independent from family doctors is currently being implemented (e.g., North region of Portugal), in which the individuals receive an FIT kit to collect the sample at home and then deliver it to their health unit. This new methodology may have an effect on the results presented.

\section{Strengths and Limitations}

This is a cross-sectional study, so it is not possible to assess the direction of the associations or to establish causal relationships. However, health surveys are designed to be representative of the study population and the synchronous measurement of dependent and independent variables is adequate to explore factors associated with outcomes of interest [38].

This investigation intends to identify sociodemographic, economic, and access-to-healthcare factors that 
may influence the use of FIT and colonoscopy. We recognize, however, that there are other important factors that were not possible to include in this study. The use of exams, especially colonoscopy, may be influenced by the reason behind the prescription (preventive, therapeutic, or curative purposes), by the use of public or private health services, and by disparity between procedures among doctors.

The reasons for the regional asymmetries found regarding the proportions of users of the exams remain improperly clarified, mainly because they do not match the CRC screening program implementation panorama in Portugal at that time.

The missing values for the variables of FIT and colonoscopy use were excluded from the statistical analysis. For FIT, the missing values corresponded to $7.8 \%(n=$ 194). For colonoscopy, they corresponded to $2.4 \%$ ( $n=$ 59). These missing values may have resulted from a refusal to answer, memory bias, or the individual not being able to recognize the exam.

Compared to the 2014 NHS, INSEF registered higher proportions of users for FIT and colonoscopy and lower percentages of missing values. This may be due to the fact that the INSEF questionnaire was applied by a trained health professional [19]. However, the short period of time between the 2 surveys raises the hypothesis of bias through social desirability.

In order to minimize the selection bias, we calibrated for sex, age, and health region [19]. We point out that individuals who accepted to participate in INSEF may be the people more concerned with their health status and more predisposed to using the exams. The fact that INSEF data are self-reported may result in information bias. Part of the questions is related to a past time, which may result in memory bias. The sampling error was minimized by obtaining a sample of an adequate size.

We used a representative sample for the Portuguese population aged 50-74 years. However, extrapolation to foreign populations may be limited, especially if there is a significant cultural or social difference, a different type of national health service, or if the country is in a different phase of implementation of the CRC screening program.

\section{Conclusions}

In our study, the use of FIT and colonoscopy in the Portuguese population was influenced by sociodemographic, economic, and access-to-healthcare factors.

Use of FIT and Colonoscopy in Portugal
The use of FIT was statistically higher in older individuals and in individuals with an assigned family doctor. The use of colonoscopy was higher in older individuals and among those with a higher economic capacity and an assigned family doctor. Given the fact that these are the exams that are the basis for the CRC screening program in Portugal, these findings may be helpful to improve the screening uptake and guide interventions in this area. According to our results, it may be important to direct awareness campaigns and promote active recruitment strategies among the younger age groups of the eligible population. It is also important to reinforce the role of family doctors in adequate implementation of the CRC screening program given the fact that their systematic contact with patients allows them to promote educational interventions and health literacy. It could also be helpful if the individuals invited to use the exams (particularly in the context of screening) could benefit from some kind of decision aid tool or application to personalized clarification of doubts.

It is essential to broaden the CRC screening program to the whole population, as well as to implement it in accordance with guidelines throughout the whole country. Once again, we suggest that family doctors are important agents in the adequate and equitable implementation of the program.

Additional investigations should be carried to complement and explain some of the results of this study, mitigate its limitations, and clarify issues that remain dubious, i.e., the reasons behind the regional asymmetries that were found. We think it would be important to develop qualitative studies to better understand the factors linked to the uptake of the exams from the individuals' perspective. It is also important to investigate how these results may have been altered by the changes that have occurred in the meantime in the Portuguese context (e.g., exemption from payment for exams in health units with convention with the National Health Service; progress in terms of implementation of the screening program in the various regions; and new methodologies of implementation). From a public health perspective, it would be important to investigate in particular the factors related to the individuals who are simultaneously nonusers of both exams (nonscreened individuals).

\section{Acknowledgement}

The authors are grateful to all of the professionals that were involved in the INSEF fieldwork and to all of the INSEF participants. 


\section{Statement of Ethics}

The INSEF study received ethical approval from the Ethics Commission of the Portuguese National Health Institute Doutor Ricardo Jorge, the National Data Protection Authority (No. 9348/2010), and all of the project partners' ethics commissions. All of the participants signed a written informed consent form.

\section{Conflict of Interest Statement}

The authors have no conflict of interests to declare.

\section{Funding Sources}

INSEF was developed as part of the predefined project of the Public Health Initiatives Program "Improvement of epidemiological health information to support public health decision and man- agement in Portugal: Towards reduced inequalities, improved health, and bilateral cooperation", which benefited from a EUR 1,500,000 grant from Iceland, Liechtenstein, and Norway through the European Economic Area Grants and from the Government of Portugal.

\section{Author Contributions}

F.S.G. and I.K. contributed substantially to the conception and design of this study; the acquisition, analysis, and interpretation of data; and drafting of the first version of this work. D.S., E.C., and B.N. contributed substantially to the conception and design of this study and the acquisition and interpretation of data, and they critical revised this article. All of the authors gave their final approval of the version to be published and agreed to be accountable for all aspects of this work in ensuring that questions related to the accuracy or integrity of any part of this work are appropriately investigated and resolved.

\section{References}

1 European Commission. ECIS - European Cancer Information System [Internet]. Brussels: European Commission; 2020 [cited 2021 Jan 31]. Available from: https://ecis.jrc.ec.europa.eu.

2 Ferlay J, Colombet M, Soerjomataram I, Dyba T, Randi G, Bettio M, et al. Cancer incidence and mortality patterns in Europe: estimates for 40 countries and 25 major cancers in 2018. Eur J Cancer. 2018 Nov;103:356-87.

3 Organisation for Economic Co-operation and Development. Health at a glance: Europe 2018 - state of health in the EU cycle. Paris: OECD; 2018

4 Organisation for Economic Co-operation and Development. Health at a glance 2019: OECD indicators. Paris: OECD; 2019.

5 Eurostat. Cancer statistics: statistics explained [Internet]. Brussels: European Statistical Office; 2019 [cited 2021 Jan 31]. Available from: https://ec.europa.eu/eurostat/statistics-explained/index.php?title=Cancer_statistics.

6 International Agency for Research on Cancer; World Health Organization. Globocan 2020 [Internet]. Lyon: IARC; 2020 [cited 2021 Jan 31]. Available from: https://gco.iarc.fr/.

7 Navarro M, Nicolas A, Ferrandez A, Lanas A. Colorectal cancer population screening programs worldwide in 2016: an update. World J Gastroenterol. 2017 May;23(20):3632-42.

8 Cross AJ, Robbins EC, Saunders BP, Duffy SW, Wooldrage K. Higher adenoma detection rates at screening associated with lower long-term colorectal cancer incidence and mortality. Clin Gastroenterol Hepatol. 2020, Online ahead of print.

9 Jodal HC, Helsingen LM, Anderson JC, Lytvyn L, Vandvik PO, Emilsson L. Colorectal cancer screening with faecal testing, sigmoid- oscopy or colonoscopy: a systematic review and network meta-analysis. BMJ Open. 2019 Oct;9(10):e032773.

10 European Commission. Directorate General for Health and Consumer Affairs. European guidelines for quality assurance in colorectal cancer screening and diagnosis. Brussels: Publications Office of the European Union; 2012.

11 von Karsa L, Patnick J, Segnan N, Atkin W, Halloran S, Lansdorp-Vogelaar I, et al.; European Colorectal Cancer Screening Guidelines Working Group. European guidelines for quality assurance in colorectal cancer screening and diagnosis: overview and introduction to the full supplement publication. Endoscopy. 2013;45(1):51-9.

12 Labianca R, Nordlinger B, Beretta GD, Mosconi S, Mandalà M, Cervantes A, et al.; ESMO Guidelines Working Group. Early colon cancer: ESMO Clinical Practice Guidelines for diagnosis, treatment and follow-up. Ann Oncol. 2013 Oct;24(6 Suppl 6):vi64-72.

13 Ministério da Saúde Portugal. Direção-Geral da Saúde: Programa Nacional para as Doenças Oncológicas 2017. Lisbon: DGS; 2017.

14 Ministério da Saúde Portugal. Direção-Geral da Saúde: Relatório de monitorização e avaliação dos rastreios oncológicos 2016. Lisbon: DGS; 2017.

15 Martins C, Azevedo LF, Ribeiro O, Sá L, Santos $\mathrm{P}$, Couto $\mathrm{L}$, et al. A population-based nationwide cross-sectional study on preventive health services utilization in Portugal: What services (and frequencies) are deemed necessarybypatients?.PLoSOne.2013;8(11):e81256.

16 Brotons C, Bulc M, Sammut MR, Sheehan M, Martins CM, Björkelund C, et al. Attitudes toward preventive services and lifestyle: The views of primary care patients in Europe -
The EUROPREVIEW patient study. Fam Pract. 2012;29:i168-i176.

17 US Department of Health and Human Services. Centers for Disease Control and Prevention: Access to health services - US Department of Health and Human Services. Center for Disease Control and Prevention. Healthy People 2020 midcourse review. Atlanta: CDC; 2014. pp. 1-11.

18 Miller NA, Kirk A, Alston B, Glos L. Effects of gender, disability, and age in the receipt of preventive services. Gerontologist. 2014 Jun;54(3):473-87.

19 Nunes B, Barreto M, Gil AP, Kislaya I, Namorado $S$, Antunes L, et al. The first Portuguese National Health Examination Survey (2015): design, planning and implementation. J Public Health (Oxf). 2019 Sep;41(3):511-7.

20 Harris PA, Taylor R, Thielke R, Payne J, Gonzalez N, Conde JG. Research electronic data capture (REDCap) - a metadata-driven methodology and workflow process for providing translational research informatics support. J Biomed Inform. 2009 Apr;42(2):377-81.

21 Hassan C, Quintero E, Dumonceau JM, Regula J, Brandão C, Chaussade S, et al.; European Society of Gastrointestinal Endoscopy. Post-polypectomy colonoscopy surveillance: European Society of Gastrointestinal Endoscopy (ESGE) guideline. Endoscopy. 2013 Oct;45(10):842-51.

22 Tamhane AR, Westfall AO, Burkholder GA, Cutter GR. Prevalence odds ratio versus prevalence ratio: choice comes with consequences. Stat Med. 2016 Dec;35(30):5730-5.

23 Aguiar P, Nunes B. Odds ratio: reflexão sobre a validade de uma medida de referência em epidemiologia. Acta Med Port. 2013 SepOct;26(5):505-10. 
24 Held L, Sabanés Bové D. Likelihood. In: Held L, editor. Sabanés Bové D. Likelihood and Bayesian inference: With applications in biology and medicine. 2nd ed. Berlin: Springer; 2020. pp. 13-50.

25 Lulmley T. Analysis of complex survey samples. J Stat Softw. 2004;9 i08.

26 Eurostat. Health overview: preventive services - complete database [Internet]. Brussels: European Statistical Office; 2019 [cited 2021 Jan 31]. Available from: https://ec.europa.eu/ eurostat/web/health/data/database.

27 Costa AR, Silva S, Moura-Ferreira P, VillaverdeCabral M, Santos O, Carmo ID, et al. Cancer screening in Portugal: sex differences in prevalence, awareness of organized programmes and perception of benefits and adverse effects. Health Expect. 2017 Apr;20(2):211-20.

28 Instituto Nacional de Estatística. Inquérito Nacional de Saúde 2014. Lisbon: INE; 2016.

29 Wools A, Dapper EA, de Leeuw JR. Colorectal cancer screening participation: a systematic review. Eur J Public Health. 2016 Feb;26(1):15868.
30 Mansouri D, McMillan DC, Grant Y, Crighton EM, Horgan PG. The impact of age, sex and socioeconomic deprivation on outcomes in a colorectal cancer screening programme. PLoS One. 2013 Jun;8(6):e66063.

31 Davis JL, Buchanan KL, Katz RV, Green BL. Gender differences in cancer screening beliefs, behaviors, and willingness to participate: implications for health promotion. Am J Men Health. 2012 May;6(3):211-7.

32 García AZ. Factors influencing colorectal cancer screening participation. Gastroenterol Res Pract. 2011;12(483417).

33 Friedemann-Sánchez G, Griffin JM, Partin MR. Gender differences in colorectal cancer screening barriers and information needs. Health Expect. 2007 Jun;10(2):14860.

34 Wong RK, Wong ML, Chan YH, Feng Z, Wai $\mathrm{CT}$, Yeoh KG. Gender differences in predictors of colorectal cancer screening uptake: a national cross sectional study based on the health belief model. BMC Public Health. 2013 Jul;13(1):677.
35 Eurostat. Healthcare activities statistics: preventive services [Internet]. Brussels: European Statistical Office; 2018 [cited 2021 Jan 31]. Available from: https://ec.europa.eu/eurostat/statistics-explained/index.php/Healthcare_activities_statistics_-_preventive_services.

36 Khalid-de Bakker C, Jonkers D, Smits K, Mesters I, Masclee A, Stockbrügger R. Participation in colorectal cancer screening trials after first-time invitation: a systematic review. Endoscopy. 2011 Dec;43(12):105986.

37 Senore C, Inadomi J, Segnan N, Bellisario C, Hassan C. Optimising colorectal cancer screening acceptance: a review. Gut. 2015 Jul;64(7):1158-77.

38 Bonita R, Beaglehole R, Kjellström T. Chapter 3: Types of studies. In: Bonita R, Beaglehole R, Kjellström $\mathrm{T}$, editors. Basic epidemiology. 2nd ed. Geneva: World Health Organization; 2006. p. 44. 